Süleyman Demirel Üniversitesi Fen Edebiyat Fakültesi Fen Dergisi

Atıf için / For Citation: G. Yakalı, "Halojen atomları ve siyano grubunun hekzasen molekülünün optik, elektronik ve yük transfer özellikleri üzerine etkisinin incelenmesi: moleküler dizayn yöntemi, yapı-özellik ilişkisi”, Süleyman Demirel Üniversitesi Fen Edebiyat Fakültesi Fen Dergisi, 15(2), 330-342, 2020.

\title{
Halojen Atomları ve Siyano Grubunun Hekzasen Molekülünün Optik, Elektronik ve Yük Transfer Özellikleri Üzerine Etkisinin İncelenmesi: Moleküler Dizayn Yöntemi, Yapı-Özellik İlişkisi
}

\author{
Gül YAKALI ${ }^{* 1}$

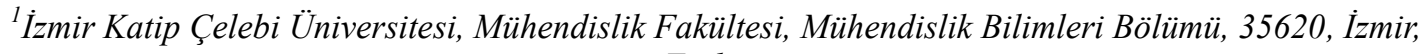 \\ Türkiye \\ *yazışılan yazar e-posta: gul.yakali@ikc.edu.tr
}

(Alinış / Received: 15.10.2020, Kabul / Accepted: 24.11.2020, Yayımlanma / Published: 29.11.2020)

Özet: Bu çalışmada, $\pi$-konjugasyon yapısına sahip hekzasen molekülü, farklı halojen atomlar (Flor, Klor, Brom) ve molekülde farklı konumlandırılmış siyano grupları ile dizayn edilmiş, elektronik, optik ve yük transfer özellikleri zamana bağlı ve zamandan bağımsız Yoğunluk Fonksiyon Teorisi (YFT) ile incelenmiştir. Dizayn edilen beş hekzasen türevinin yap1 ve özellik arasındaki ilişkiyi kurabilmek için, moleküler geometri, reorganizasyon enerji, HOMO-LUMO orbital enerjileri, iyonizasyon potansiyeli (IP), elektron afinitesi (EA), geometriden dolayı nötr ve yüklü durumlara bağlı olarak bağ uzunluğu değiş̧imi (BUD) üzerine substitüe etkisi incelenmiş ve etkiyi daha iyi anlayabilmek için sonuçlar hekzasen ve antrasen moleküllerin sonuçlarıyla karşılaştırılmıştır. Moleküllerin, elektron enjeksiyon bariyerinin hekzasen molekülünden daha düşük olduğu ve iyi bir boşluk taşıyıcısı olarak bilinen antrasen molekülüyle kıyaslanabilir derecede etkili boşluk yük transfer oranına sahip olduğu belirtilmiştir. Dizayn edilen hekzasen türevlerinin, optoelektronik alanda potansiyel uygulamalar için ilgi çekebileceğini ve malzeme biliminde umut vaad edeceğini umuyorum.

Anahtar kelimeler: Yoğunluk fonksiyon teorisi, İyonizasyon potansiyeli, Elektron afinitesi, Reorganizasyon enerji, Marcus teori, Yük taşıma oranı.

\section{Studying the Effect of Halogen Atoms and the Cyano Groups on Optical, Electronic and Charge Transfer Properties of Hexacene Molecule: Molecular Design Methods, Structure-Property Relationship}

\begin{abstract}
In this study, the $\pi$-conjugated hexacene molecule was designed with different halogen atoms (Fluorine, Chlorine, Bromine), differently positioned cyano groups and its electronic, optical and charge transfer properties were investigated by time-dependent and time-independent Density Functional Theory (DFT). The substituent effect on the molecular geometry, reorganization energy, frontier orbitals, ionization potential (IP) and bond length alternation (BLA) depending on nötr and charged states, electronic affinity (EA) of the five molecules were investigated to establish the relationship between structures and properties .To gain a better understanding of the substituent effect on the charge transport property, the results of designed molecules were compared with hexacene and antracene molecules. The electron injection barrier of the new designed molecules is lower than hexacene molecule and have more effective hole charge transfer property which is comparable to that of antracene known as a good hole charge carrier. I belived that, new designed hexacene derivatives may be used as optoelectronic devices which could attract great attention in material sciences.
\end{abstract}

Key words: Density functional theory, Iyonization potential, Electron affinity, Reorganization energy, Marcus theory, Charge carrier rate. 


\section{Giriş}

$\pi$-konjuge yapısına sahip olarak dizayn edilen organik optoelektronik malzemeler aktif bir şekilde çalışılmakta ve malzeme biliminde sahip olduğu uygulama alanlarından dolayı önemli derecede ilgi çekmektedir [1-3]. Bu malzemeler, 1şık yayıcı diyotların (LED), alan etkili transistörlerin ve güneş pillerinin uygulanmasında ciddi bir potansiyele sahiptirler. $\pi$-konjuge yapılar, fonksiyonel organik materyaller olarak pratikte ilgi çekmelerinin yanı sıra teorik olarak da kayda değer derecede öneme sahiptirler [4-5]. Yüksek potansiyele sahip, tercih edilen optik ve elektronik özellikleri içeren malzemeler üretmek için en iyi yöntem, teorik yöntemleri kullanarak yeni moleküller dizayn etmektir [6-7]. Çünkü; uzun yıllar boyunca $\pi$-konjuge yapıların belirli optik ve elektronik özelliklere sahip olması için sentezlenmesi, cihaz performansını arttırmada bir zorluk teşkil etmiştir. Moleküler modelleme yöntemi, aynı molekülün karakterizasyonu ve sentezlenmesine ayrılan zamandan çok daha kısa bir zaman almaktadır. Bu sebeple optoelektronik cihaz olarak kullanılmak istenilen moleküllerin sentezlenmeden önce teorik olarak modellenmesi ve optik-elektronik özelliklerinin incelenmesi daha çok tercih edilen bir durum haline gelmiştir [8-10]. Poli aromatik sistemler, moleküler modelleme yöntemleri için en uygun temel yapılardır. Çünkü; bu yapılar kararlılık, yapısal esneklik ve enerji band aralığının düşmesini $(\Delta E)$ sağlayan yükün delokolizasyonu özelliklerini içerdikleri için moleküller arası yük transportunun artmasını, dolayısıyla optoelektronik cihazda performans ve verim artmasını sağlarlar [11].

$\mathrm{N}$ tane düzlemsel benzen halkalarının lineer zincirlerinden ve $\pi$-konjuge yapılardan oluşan $\mathrm{n}$ asenler (tetrasen, pentasen, hekzasen vb.) aromatik hidrokarbonların bir sinıfını oluşturmaktadır [12]. Bu yapıların en çarpıcı özelliklerinden biri, dar HOMO-LUMO band enerji aralığına sahip olmasıdır ki bu durum diğer organik moleküllerle kıyaslandığında daha yüksek bir elektik iletkenliği sağlamaktadır [13]. Pentasen, hekzasen gibi büyük yapılı asenler oldukça geniş bir uygulama alanına sahip olmalarına rağmen, bu yapıların etkinlikleri çözücü içerisinde sahip oldukları düşük çözünürlük ve düşük kararlılıktan dolayı sınırlandırılmaktadır [14-15]. Bu çalışmanın ana amacı ise, hekzasen molekülünün farklı halojen atomlar $(\mathrm{F}, \mathrm{Cl}, \mathrm{Br}$,$) ve molekülde farklı$ konumlandırılan fonksiyonel gruplar $(\mathrm{CN})$ bağlandığında, molekülün elektronik özellikleri ve moleküler yapı arasındaki ilişkiyi inceleyerek elektronik yapıların teorik analizini gerçekleştirmek ve bu özelliklerin optik absorpsiyon spektrumu ve yük taşıma kapasitesi üzerine etkisini araştırmaktır. Konjugasyon bileşiklerinin elektronik yapılarının teorik çalışması, bilinen moleküllerin özelliklerinin optimizasyonuna büyük katkı yapmakta ve bilinmeyen moleküllerin de yapılarını tayin etmede önemli bir yere sahiptir [16]. Bu nedenle, bu çalışmanın düşük band aralıklı ve düşük reorganizasyon enerjili dolayısıyla, yüksek yük taşıma kapasiteli yeni $\pi$-konjuge moleküllerinin sentezinde yol gösterici olacağına inanmaktayım.

Fonksiyonel $\pi$-konjuge sistemlerin sentezinde, HOMO (işgal edilmiş en yüksek moleküler orbital) ve LUMO (işgal edilmemiş en düşük moleküler orbital) enerji seviyelerinin kontrolü önemli bir yere sahiptir. Moleküler dizayn çalışmaları, malzemelerin elektrik ve optik özelliklerini belirleyen band aralığı enerji değeri $(\Delta E=\mathrm{HOMO}-\mathrm{LUMO})$ hakkında bize bilgi vermektedir.

$$
\Delta E=\mathrm{E}_{\mathrm{BLA}}+\mathrm{E}_{\mathrm{Res}}+\mathrm{E}_{\mathrm{Sub}}+E_{\theta}+\mathrm{E}_{\mathrm{Int}}
$$


Band aralığg enerji değerini $(\Delta E)$ belirleyen yapısal faktörler Denklem 1'de gösterilmiştir [14]. Band aralığını düşürmenin en etkili yollarından biri, $E_{B L A}$ ( bağ uzunluğu değişim enerjisi) enerjisinin düşürülmesidir. BLA, polimer zincirinde $\left((\mathrm{CH})_{\mathrm{n}}\right)$ komşu karbon-karbon bağları arasındaki uzunluğun ortalama farkı olarak tanımlanır [17]. Elektron fonon $(\mathrm{C}-\mathrm{C})$ çiftlenmesi ve elektron-elektron korelasyon etkisinin konjuge sistemlerde $\pi$-elektronlarının lokalizasyonunu arttırmasından dolayı, konjuge sistemler karasız olup bütün $\mathrm{C}-\mathrm{C}$ bağları eşit uzunluğa sahip değildir. Dolayısıyla, moleküllerdeki düşük BLA değeri, band aralığı enerji değerinin de düşmesini sağlayacaktır. Bu çalışmada moleküllerin BLA değerleri nötr geometri, anyon geometri ve katyon geometri durumundaki optimize bağ uzunlukları karşılaştırılarak hesaplanmıştır.<smiles>c1ccc2cc3cc4cc5cc6ccccc6cc5cc4cc3cc2c1</smiles>

Hekzasen (H)<smiles></smiles>

1, 2,3,4,9,10,11,12-oktabromohekzasen (BH)<smiles>N#Cc1cccc2cc3cc4cc5cc6c(C#N)cccc6cc5cc4cc3cc12</smiles><smiles>Fc1c(F)c(F)c2cc3cc4cc5cc6c(F)c(F)c(F)c(F)c6cc5cc4cc3cc2c1F</smiles>

1, 2,3,4,9,10,11,12-oktaflorohekzasen (FH)<smiles>Clc1c(Cl)c(Cl)c2cc3cc4cc5cc6c(Cl)c(Cl)c(Cl)c(Cl)c6cc5cc4cc3cc2c1Cl</smiles>

1, 2,3,4,9,10,11,12-oktaklorohekzasen (KH)<smiles>N#Cc1c2ccccc2cc2cc3cc4c(C#N)c5ccccc5cc4cc3cc12</smiles>

8,16-disiyanohekzasen (SH2)

Şekil 1. Moleküllerin kimyasal yapıları.

Düşük band aralığı enerjisi elde etmenin bir diğer etkili yollarından biri, molekülün iskelet yapısına donör veya akseptör gruplarının bağlanmasıdır [17-19]. $\pi$-konjuge yapılara, elektron donör ve akseptör gruplarının bağlanması, HOMO enerji seviyesinin artmasını sağlar ve sonuç olarak $\Delta E$ değeri düşer. Bu katkı denklemde $\mathrm{E}_{\text {Sub }}$ ile temsil edilir. Optoelektronik cihazlarda, donör-akseptör bileşenlerinin HOMO ve LUMO enerji seviyeleri, moleküller arasında ki etkili yük transferini belirlemek için önemli faktörlerdir.

Teorik çalışmalara bağlı olarak, taban durumunda kinoid karaktere sahip olan yapılar düşük band aralığı enerji değerini içerirler. Aromatik yapılar enerjik olarak daha kararlı yapıya sahipken, kinoid yapılar yüksek enerjiye sahiptir [20]. Örneğin, altılı benzen halkasına çift bağlı iki oksijen atomunun bağlanması sonucu yapı kinoid sistem halini alır. $\mathrm{Bu}$ durumda, yapının kinoid karakteri artacak ve aromatik kısımların aromatik stabilizasyon rezonans enerjisi azalacaktır. $\mathrm{Bu}$ etki, band aralı̆̆ enerji değerinin düşmesine katkı sağlayacaktır. Denklemde bu faktör $E_{R e s}$ ile temsil edilmektedir. 
Denklemdeki $\theta$ faktörü halka ve molekül düzlemi arasındaki dihedral açıdır ki konjuge yapı boyunca $\pi$-elektronlarının delokalizasyonunu kısıtlar. $\theta$ açısı ne kadar düşükse molekül o kadar düzlemsel ve kararlı, dolayısıyla band aralığı enerjisi düşük, yük mobilitesi o kadar iyi olacaktır.

Elektron transfer teorisi, moleküllerin n tipi ya da p tipi olup olmadıklarının, diğer bir deyişle yük taşıyıcılarının elektronlar $\mathrm{m}$ ı ya da boşluklar mı olup olmadığının anlaşılmasını ve malzemelerde elektron transferinin geliştirilmesini sağlar [21-23]. Elektron transfer oranın geliştirilmesini sağlayan en önemli faktör reorganizasyon enerjisidir [24]. Reorganizasyon enerjisi iç ve dış olmak üzere iki grupta toplanır. İç reorganizasyon enerji, bir moleküle elektron eklendiğinde (anyon hal) ve molekülden bir elektron uzaklaştırıldığında ki (katyon hal) moleküler geometri modifikasyonunu içerir. Dış reorganizasyon enerjisi ise, polarizasyon etkisinden dolayı molekülü çevreleyen ortamın modifikasyonunu kapsar [25]. Küçük reorganizasyon enerji değeri, yüksek oranda yük transport değerini vererek, optoelektronik malzeme tasarımında istenen bir özelliktir.

Genel olarak, bu makalede Yoğunluk Fonksiyon Teorisi (YFT) ve Zamana Bağlı Yoğunluk Fonksiyon Teorisi Yöntemi kullanılarak farklı halojen (Flor, Klor ve Brom) atomlar bağlanan ve farklı konumlarda siyano $(\mathrm{CN})$ grubu içeren 5 hekzasen molekülünün elektronik yapısı, absorpsiyon-emisyon özellikleri ve yük transfer özellikleri ( iyonizasyon potansiyeli, elektron çekiciliği ve reorganizasyon enerji) çalışılmıştır. Bu hesaplamalar sonucunda moleküllerin p- tipi moleküller olduğuna ve yük taşıyıcılarının boşluklar aracılığıyla yapıldığına karar verilmiştir. Ayrıca moleküllerin reorganizasyon enerji değerlerinden yola çıkılarak, yük transfer kapasitelerine yorum getirilmiştir. Moleküllerin kimyasal yapıları Şekil 1'de gösterilmiştir. Sonuç olarak, halojen grup bağlanarak yeni dizayn edilen moleküllerin yük transfer özellikleri, hekzasen molekülüne göre daha etkili ve iyi bir boşluk yük taşıyıcısı olarak bilinen antrasen molekülününkiyle de kıyaslanabilir derecededir. Siyano gurubu bağlanan yapılarda reorganizasyon enerji değeri hekzasen molekülünden yüksektir. Böyle durumlarda yük taşıma kapasitesine karar verebilmek için Marcus Teoremi'nden yola çıkarak, moleküllerin transfer integral değeri de hesaplanmalıdır. Yüksek transfer integral değeri ve düşük reorganizasyon değeri moleküllerde yük taşıma kapasitesini arttırır. Bu çalışmada, moleküllerin transfer integral değeri ADF (Amsterdam Density Functional) programını kullanma yetkisi olmadığından dolayı hesaplanamamıştır. Sonuç olarak, bu bulgular, çalışmadaki gibi türevlendirilen hekzasen moleküllerinin etkili boşluk yük aktarım oranına sahip optoelektronik malzemeler olarak umut verici yapılar olduğunu göstermektedir.

\section{Materyal ve Yöntem}

Yoğunluk Fonksiyon Teorisi ve Zamana Bağlı Yoğunluk Fonksiyon Teorisi çalışmaları organik malzemelerin optik ve elektronik özelliklerinin anlaşılmasında yaygın kullanılan hesaplama yöntemleridir. $\mathrm{Bu}$ çalışmada, Gaussian 09 paket programı aracılığıyla B3LYP fonksiyonel ve 6-311G (d,p) baz setleri kullanılmıştır [26-30]. Hesaplanan reorganizasyon enerjisi, nötr durumdan iyonize duruma geçerken (katyon ya da anyon durumundaki geometrik hal) ya da tersi durumda, moleküllerdeki geometrik değişimleri yansıtan iç reorganizasyon enerjisi olarak tanımlanmıştır. Moleküllerin yük aktarım davranışı Marcus Teorisi ile ifade edilir. Marcus teorisine göre yük transfer oranı aşağıdaki eşitlik ile belirlenir [25]. 


$$
W=\frac{V^{2}}{h}\left(\pi / \lambda k_{B} T\right)^{1 / 2} \exp \left(-\lambda / 4 k_{B} T\right)
$$

Marcus Teorisine göre, yük transfer oranı Denklem 2 ile belirlenir [32]. Burada etkili yük transferi için reorganizasyon enerji değerinin en az $(\lambda)$, transfer integralinin $(V)$ en fazla olması gerekmektedir [31]. $\lambda$ reorganizasyon enerjisi, $\lambda_{r e l}^{1}$ ve $\lambda_{r e l}^{2}$ olmak üzere iki kısıma ayrılır. $\lambda_{r e l}^{1}$, bir molekülün nötr durumdan yüklü duruma geçerken ki geometrik relaksasyon enerjisine karşılık gelir. $\lambda_{r e l}^{2}$ için ise tersi durum söz konusudur.

$$
\lambda=\lambda_{r e l}^{1}+\lambda_{r e l}^{2}
$$

$\mathrm{Bu}$ iki terim doğrudan adyabatik potansiyel enerji yüzeylerinden hesaplanmış olup Denklem 3'de gösterilmiştir [31-32].

$$
\begin{aligned}
& \lambda_{\text {anyon }}=\lambda_{\text {rel }}^{1}+\lambda_{\text {rel }}^{2}=\left[E^{(1)}(M)-E^{(0)}(M)\right]+\left[E^{(1)}\left(M^{-}\right)-E^{(0)}\left(M^{-}\right)\right] \\
& \lambda_{\text {katyon }}=\lambda_{\text {rel }}^{1}+\lambda_{\text {rel }}^{2}=\left[E^{(1)}(M)-E^{(0)}(M)\right]+\left[E^{(1)}\left(M^{+}\right)-E^{(0)}\left(M^{+}\right)\right]
\end{aligned}
$$

Denklem 3 ve Denklem 4 sırasıyla boşluk ve elektron reorganizasyon enerji değeri formüllerini göstermektedir. Burada $E^{(1)}(M)$, yüklü optimize geometride (anyon ya da katyon) nötr molekül enerjisi, $E^{(0)}(M)$ nötr gometrideki taban durum enerjisidir. $E^{(1)}\left(M^{-}\right)-E^{(1)}\left(M^{+}\right)$optimize edilmiş nötr geometride ki anyonik ve katyonik enerji farkıdır. $E^{(0)}\left(M^{-}\right)-E^{(0)}\left(M^{+}\right)$terimi ise yüklü durumların taban durum enerji farkıdır. Moleküllerin hesaplanan reorganizasyon enerji değerleri Tablo 2'de gösterilmiştir.

Optimize edilmiş elektronik cihazların rasyonel tasarımı için etkili boşluk ve elektron enjeksiyon değerinin önemli olduğu iyi bilinmektedir. Moleküler iyonlaşma potansiyeli (IP) ve elektron afinite (EA), organik cihaz performans1 ve ortam kararlılığ 1 ile ilgili bilgiler vermektedir. Bir bileşiğin IP ve EA değerleri, moleküldeki elektron ve boşlukların enjeksiyonu için enerji bariyerini hesaplamakta kullanılırlar. İyonizasyon enerjisi hesaplanmasında, adyabatik iyonizasyon potansiyeli (IPa) ve dikey iyonizasyon potansiyeli (IPv) Denklem 6'ya göre hesaplanmıştır.

$$
I P a=E^{0}(M)^{+}-E^{0}(M), \quad I P v=E^{0}(M)^{+}-E^{0}(M)
$$

Tüm moleküllerin adyabatik (EAa) ve dikey elektron afinitesi (EAv) Denklem 7'deki gibi hesaplanmıştır.

$$
E A a=E^{0}(M)-E^{0}(M)^{-}, \quad E A v=E^{0}(M)^{-}-E^{1}(M)^{-}
$$

Moleküllerin IP ve EA değerleri Tablo 3'te gösterilmiştir.

\section{Bulgular}

\subsection{Yapıların Elektronik Özellikleri}


Moleküllerin en uygun optimize geometrileri B3LYP/6-311G (d,p) baz setiyle elde edilmiş ve Şekil 2'de gösterilmiştir.
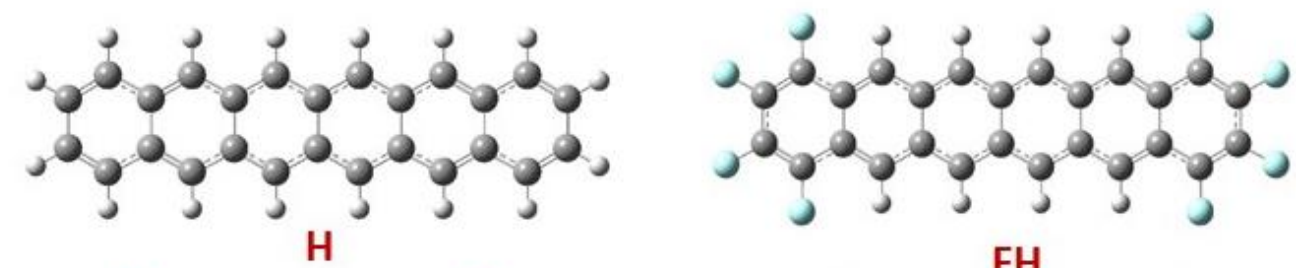

FH
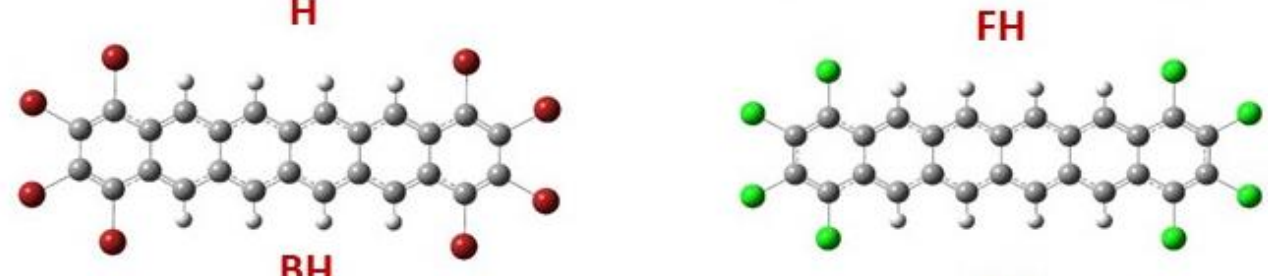

$\mathrm{BH}$

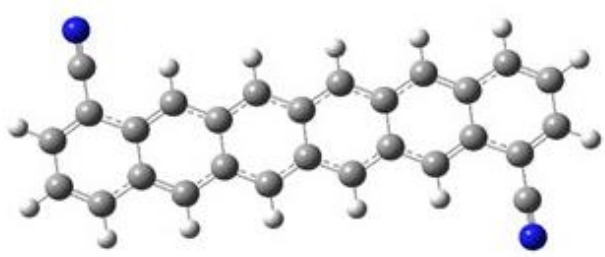

SH1

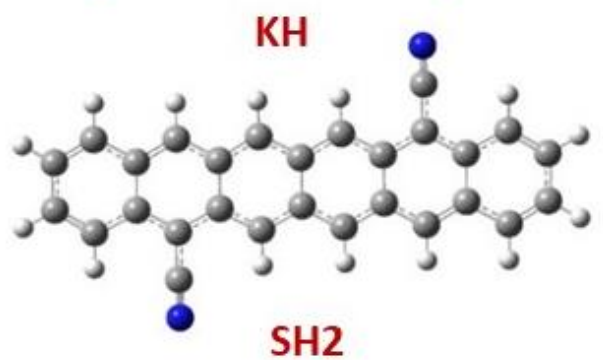

Şekil 2. Moleküllerin en uygun optimize geometrileri.

Tablo 1. Moleküllerin Teorik Olarak Hesaplanan Elektronik Yapı Parametreleri Değerleri

\begin{tabular}{|c|c|c|c|}
\hline Molekül & $\mathbf{E}_{\mathbf{L u M O}}(\mathbf{e V})$ & $\mathbf{E}_{\text {HOMO }}(\mathbf{e V})$ & $\mathbf{E}_{\text {gap }}(\mathbf{e V})$ \\
\hline $\mathbf{H}$ & -2.86 & -4.66 & -1.8 \\
\hline FH & -3.52 & -5.31 & -1.79 \\
\hline BH & -3.61 & -5.37 & -1.76 \\
\hline KH & -3.68 & -5.45 & -1.77 \\
\hline SH1 & -3.45 & -5.20 & -1.75 \\
\hline SH2 & -3.58 & -5.30 & -1.72 \\
\hline
\end{tabular}

Taban durum için en yüksek işgal edilmiş moleküler orbital (HOMO) ve en düşük işgal edilmemiș moleküler orbital görüntüleri Şekil 3'de mevcuttur. Tablo 1'de moleküllerin elektronik yapı parametreleri (HOMO, LUMO, band aralığı enerjisi) gösterilmektedir. Hesaplanan band aralık enerji değerleri 1.70 ile $1.80 \mathrm{eV}$ arasında olup $\mathrm{H}>F \mathrm{H}>\mathrm{KH}>$ $\mathrm{BH}>\mathrm{SH} 2>\mathrm{SH} 1$ düzenindedir.

Şekil 3'de görüldüğg̈ gibi bütün moleküllerde HOMO ve LUMO dağılımları molekül iskelet yapısı boyunca ilerlemektedir. Moleküllerdeki bütün gruplar HOMO ve LUMO oluşumuna katılmaktadır. Ancak, dizayn edilmiş hekzasen türevlerinde HOMOlar elektron verici grup boyunca delokalize olurken, LUMOlar elektron çekici gruplar (Flor, Brom, Klor, Siyano) üzerine delokalize olmaya çalışmaktadır. Moleküllerin taban durumda HOMO ve LUMO enerji değerleri Tablo 1'de görüldügü gibi ana molekülden (hekzasen) düşüktür. Elektron verici gruplar yüksek öncü (frontier) moleküler enerji değerleri verirken, elektron çekici gruplar düşük enerji değerinde öncü (frontier) orbital grupları oluşmasını sağlar. Elektron çekici gruplar elektron almaya meyilli olmalarından dolayı, hekzasen molekülüne halojen atomlar bağlandığı zaman LUMO enerji seviyeleri düşmüş ve molekülün iyonizasyon potansiyelinde (IP) de bir artış meydana gelmiştir. Benzer bir deyişle moleküle dışarıdan elektron verebilmenin kolaylaşması elektron afinitesinin yüksek olmasina neden olmaktadır. Elektron afinite ve iyonizasyon 
potansiyeli değerleri, elektron çekici moleküllerin bağlandığı moleküllerde daha yüksektir [33]. Güçlü elektron çekici özelliğinden dolayı en düşük enerji band aralığ 1 değeri siyano gurubunun bağlı olduğu moleküllerde görülmüştür. Modellenen 8,6disiyanohekzasen molekülü (SH2) en düşük enerji band aralığ1 değerine sahiptir.

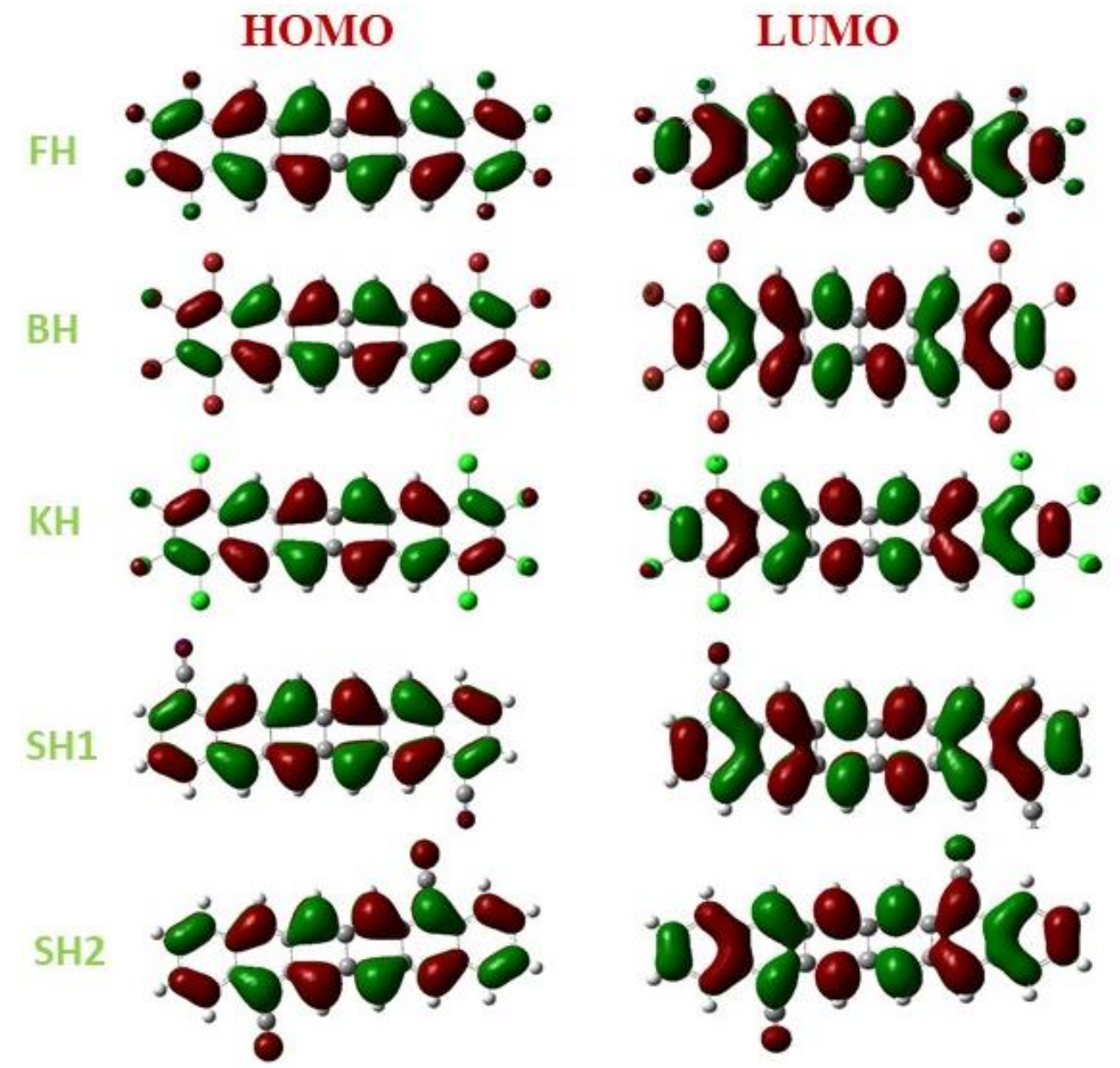

Şekil 3. Moleküllerin HOMO-LUMO görüntüleri.

Optoelektronik bir cihaz olarak tasarlanacak molekülden oluşturulacak cihazın performansı hakkında ön fikir sahip olabilmek için, boşluk ve elektron enjeksiyon değerini bilmek önem teşkil etmektedir. Örneğin, Alüminyumun iş fonksiyonu değeri $4.3 \mathrm{eV}$ 'dur [34]. Ana molekül olan hekzasenin LUMO enerji seviyesi $-2.86 \mathrm{eV}$ olup, molekülden alüminyum elektrotuna olan elektron enjeksiyon enerjisi değeri (-2.86- ($4.3))=1.44 \mathrm{eV}$ ' dur. Ana moleküle kıyasla dizayn edilen moleküllerde LUMO enerji değerleri daha düşük olup elektron enjeksiyon yeteneği yüksektir. $\mathrm{Bu}$ değerler $\mathrm{FH}, \mathrm{BH}$, $\mathrm{KH}, \mathrm{SH} 1, \mathrm{SH} 2$ molekülleri için sirasiyla $0.78 \mathrm{eV}, 0,69 \mathrm{eV}, 0.62 \mathrm{eV}, 0.85 \mathrm{eV}, 0.72 \mathrm{eV}$ değerlerindedir. Azalan enjeksiyon bariyer değerleri, yeni dizayn edilmiş hekzasen moleküllerinin, ana molekülden daha yüksek yük transfer özelliğine sahip olduğunu göstermektedir. Dolayısıyla, düşük LUMO değeri elektron enjeksiyon yeteneğini arttırmak için önemlidir. Teorik olarak modellene moleküllerin LUMO enerji düzeyleri ana molekülden daha düşük olduğundan dolayı, termodinamik olarak daha kararlı olup yük transport özellikleri elektron kaybıyla sönümlenmeyebilir.

\subsection{Moleküllerin Iyonizasyon Potansiyeli ve Elektron Afinitesi}

İyonizasyon potansiyeli ve elektron afinitesi, moleküllerin yük transfer özelliklerini belirleyen en önemli kavramlardan biridir. $\mathrm{Bu}$ iki kavram birbirlerinden farklı 
özelliklere sahip olup elektron ve boşlukların enerji bariyer enjeksiyon enerjisini belirlemek için YFT yöntemi kullanılarak hesaplanmıştır. Tablo 2'de adyabatik iyonizasyon potansiyeli (IPa), dikey iyonizasyon potansiyeli (IPv), adyabatik elektron yakınlığı (EAa) ve dikey elektron yakınlığı (EAv) değerleri gösterilmiştir.

\begin{tabular}{|c|c|c|c|c|}
\hline Molekül & $\mathbf{I P a}(\mathbf{e V})$ & $\mathbf{I P v}(\mathbf{e V})$ & $\mathbf{E A a}(\mathbf{e V})$ & $\mathbf{E A v}(\mathbf{e V})$ \\
\hline H & 5.84 & 5.96 & 1.73 & 1.59 \\
\hline FH & 6.45 & 6.52 & 2.37 & 2.30 \\
\hline BH & 6.37 & 6.43 & 2.61 & 2.55 \\
\hline KH & 6.49 & 6.54 & 2.65 & 2.58 \\
\hline SH1 & 6.34 & 7.07 & 2.34 & 1.54 \\
\hline SH2 & 6.44 & 6.63 & 2.47 & 2.14 \\
\hline
\end{tabular}

Tablo 2. Moleküllerin İyonizasyon Potansiyeli ve Elektron Afinite Değerleri

YFT hesaplamaları sonucunda, ana moleküle bağlanan elektron çekici atomlar ve farklı konumda yerleştirilen siyano grupları adyabatik ve dikey iyonizasyon potansiyelininin artmasını sağlamıştır. Bu artış, LUMO enerji seviyelerinin düşmesiyle ilgili olarak elektron enjeksiyon bariyerinin de azalmasını sağlayarak, yeni dizayn edilen moleküllerin ana moleküle kıyasla yük transportunun daha yüksek olabileceğini göstermiştir. Tablo 2' deki elektron afinite değerlerinin işaretinin tüm moleküllerde artı olması moleküllerin endotermik olabileceğini göstermiştir. Halojen atom bağlanan moleküllerin adyabatik iyonizasyon potansiyelleri sirasıyla $6.45(\mathrm{FH}), 6.37(\mathrm{BH})$ ve 6.49 $(\mathrm{KH})$ olup, siyano gurubu bağlanan moleküllerin sirasiyla 6.34 (SH1), 6.44 (SH2), değerlerindedir. Yeni tasarlanan moleküllerin ana moleküle göre elektron afinite değerlerindeki artış, etkili elektron enjeksiyon kapasitesini gösteren bir diğer temel sonuçtur. Cihaz performansında büyük elektron afinite değeri, küçük elektron enjeksiyon bariyer enerjisi anlamına gelmektedir. Dikey ve adyabatik değerler arasındaki farklar ise yapisal relaksasyonun boyutunu bize yansitmaktadır. Elektron enjeksiyon kapasitesi, halojen atomlarda $\mathrm{KH}>\mathrm{FH}>\mathrm{BH}>H$ düzeninde artış göstermektedir. Siyano grubu içeren moleküllerde ise bu düzen $S H 2>\mathrm{SH} 1>H$ durumundadir.

\subsection{Moleküllerin Reorganizasyon Enerji Hesabı}

Bu çalışmada bir moleküle elektron eklendiği ya da molekülden elektron uzaklaştırıldığı zaman moleküler geometri modifikasyonunu içeren moleküllerin iç reorganizasyon enerji değerleri Tablo 3'de gösterilmiştir [35]. Bu enerji, molekülün nötr durumdan iyonize duruma geçerken yada tam tersi durumdaki geometrik değişimleri temsil eder.

Tablo 3. Moleküllerin Reorganizasyon Enerji Değerleri

\begin{tabular}{|c|c|c|}
\hline Molekül & $\begin{array}{c}\text { Boşluk reorganizayon } \\
\text { enerjisi (eV) }\end{array}$ & $\begin{array}{c}\text { Elektron reorganizasyon } \\
\text { enerjisi (eV) }\end{array}$ \\
\hline H & 0.1889 & 0.2001 \\
\hline FH & 0.1416 & 0.1558 \\
\hline BH & 0.1049 & 0.1184 \\
\hline
\end{tabular}




\begin{tabular}{|c|c|c|}
\hline KH & 0.1206 & 0.1208 \\
\hline SH1 & 1.30 & 1.37 \\
\hline SH2 & 0.23 & 0.55 \\
\hline
\end{tabular}

Tablo 3'de görüldüğü gibi hekzasen molekülünün hesaplanan boşluk reorganizasyon enerjisi, elektron reorganizasyon enerjisinden düşüktür. Hesaplanan bu sonuç, hekzasen molekülünde yük taşıyıcılarının boşluklar olduğunu belirtmektedir. Bu durum yeni dizayn edilen moleküllerde de görülmektedir. Moleküle halojen atom bağlandığında reorganizasyon enerjisi ana moleküle göre düşmekte ve dolayısıyla Marcus Teoremi'ne göre yük taşıma kapasitesi artmaktadır. Siyano grubu bağlanan molekülleri, kendi içinde karşılaştırdığımızda en iyi yük aktarım oranına sahip SH2 molekülüdür. Siyano grubu bağlanan moleküllerde reorganizasyon enerji değeri hekzasen molekülün değerinden yüksek olmasına rağmen, yük taşıma kapasitesiyle ilgili kesin sonucu belirtebilmek için molekülün transfer integral değeri hesaplanmalıdır. Bazı moleküller çok yüksek reorganizasyon enerji değerine sahip olmalarına karşın, transfer integral değerinin etkisinden dolayı yük taşıma kapasiteleri iyi olabilmektedir. Halojen grubu bağlanan moleküllerin reorganizasyon enerji değerlerinin antrasen molekülün enerji değeriyle karşılaştırdığımızda, klor bağlanan molekülün antrasenle aynı reorganizasyon enerji değerine sahip olduğunu görürüz [36].

\subsection{Moleküllerin Absorbsiyon Spektra Analizi}

Moleküllerin hesaplanan dalga boyları Tablo 4'de verilmiştir. Ana molekül için hesaplanan absorbsiyon dalga boyu $812 \mathrm{~nm}$ olup deneysel sonuçla uyumludur [37]. FH molekülü 816.62, 521.25, $465.13 \mathrm{~nm}$ dalga boylarında, BH molekülü 838.87, 532.94, $500.62 \mathrm{~nm}$ dalga boylarında, $\mathrm{KH}$ molekülü ise $833.79,528.78,494.77 \mathrm{~nm}$ dalga boylarında absorpsiyon piki göstermektedirler. Hekzasen molekülüne 9,17 konumunda siyano grubu bağlandığında SH1 molekülünün absorpsiyon pikleri 829, 523, $481 \mathrm{~nm}$ olmaktadır. SH2 molekülü için bu değerler 887.32, 565.27, $532.12 \mathrm{~nm}$ şeklindedir. Hekzasen molekülüne elektron çekici grupların bağlanması, moleküllerin absorpsiyon piklerinin kırmızı bölgeye doğru kaymasına sebep olmaktadır.

Tablo 4. Moleküllerin Spektral Analiz Tablosu (f: titreşim şiddeti, $\lambda_{a}$ : absorpsiyon dalga boyu).

\begin{tabular}{|c|c|c|c|}
\hline Molekül & $\mathbf{f}$ & $\left.\boldsymbol{\lambda}_{\boldsymbol{a}} \mathbf{( n m}\right)$ & Transition \\
\hline H & 0.0324 & 812.24 & $\mathrm{H} \rightarrow \mathrm{L}$ \\
& 0.0013 & 508 & $\mathrm{H}-1 \rightarrow \mathrm{L} ; \mathrm{H} \rightarrow \mathrm{L}+1$ \\
& 0.0220 & 462.47 & $\mathrm{H}-1 \rightarrow \mathrm{L} ; \mathrm{H} \rightarrow \mathrm{L}+1$ \\
\hline FH & 0.03180 & 816.62 & $\mathrm{H} \rightarrow \mathrm{L}$ \\
& 0.0004 & 521.25 & $\mathrm{H}-1 \rightarrow \mathrm{L} ; \mathrm{H} \rightarrow \mathrm{L}+1$ \\
& 0.0005 & 465.13 & $\mathrm{H}-1 \rightarrow \mathrm{L} ; \mathrm{H} \rightarrow \mathrm{L}+1$ \\
\hline \multirow{3}{*}{ BH } & 0.0283 & 838.87 & $\mathrm{H} \rightarrow \mathrm{L}$ \\
& 0.01515 & 532.94 & $\mathrm{H}-1 \rightarrow \mathrm{L} ; \mathrm{H} \rightarrow \mathrm{L}+1$ \\
& 0.0544 & 500.62 & $\mathrm{H}-1 \rightarrow \mathrm{L} ; \mathrm{H} \rightarrow \mathrm{L}+1$ \\
\hline \multirow{3}{*}{ KH } & 0.0296 & 833.79 & $\mathrm{H} \rightarrow \mathrm{L}$ \\
& 0.01544 & 528.78 & $\mathrm{H}-1 \rightarrow \mathrm{L}+1 ; \mathrm{H} \rightarrow \mathrm{L}+1$ \\
& 0.34295 & 494.77 & $\mathrm{H}-1 \rightarrow \mathrm{L}+1 ; \mathrm{H} \rightarrow \mathrm{L}+1$ \\
& & & \\
\hline & 0.0408 & 829 & $\mathrm{H} \rightarrow \mathrm{L}$ \\
& 0.000253 & 523 & $\mathrm{H}-1 \rightarrow \mathrm{L} ; \mathrm{H} \rightarrow \mathrm{L}+1$ \\
& 0.03123 & 481 & $\mathrm{H}-1 \rightarrow \mathrm{L} ; \mathrm{H} \rightarrow \mathrm{L}+1$ \\
\hline \multirow{2}{*}{ SH2 } & 0.0381 & 887.22 & $\mathrm{H} \rightarrow \mathrm{L}$ \\
& 0.0025 & 565.27 & $\mathrm{H}-1 \rightarrow \mathrm{L} ; \mathrm{H} \rightarrow \mathrm{L}+1$ \\
\hline & 0.0195 & 532.12 & \\
\hline
\end{tabular}




\subsection{Moleküllerin Băg Uzunluğu Analiz Çalışması}

Dizayn edilen hekzasen türevi moleküllerin yükseltgenme (nötr durumdan enerji kaybederek katyon durumuna geçme) ve indirgenmeye (nötr durumdan elektron kazanarak anyon duruma geçme) bağlı olarak bağ uzunluğu değişiklikleri Tablo 5'de verilmiştir. Katyon ve anyon duruma geçen moleküllerin optimize geometrileri nötr geometrideki moleküllere göre değişiklik göstermiştir. Molekülde uzayan $\pi$ - konjuge yapısından dolayı (birleşmiş halka sayısı) indirgenme ve yükseltgenmeye bağlı olarak bağ uzunluğu değişikliğinin tüm molekül üzerinde olduğu görülmüştür. İndirgenmeye bağlı bağ uzunluğu olarak oksidasyona uzunluğu

yüksektir. Bu durum reorganizasyon<smiles></smiles>
değişikliği, genel bağlı bağ değişikliğinden elektron enerjisinin incelenen moleküllerin boşluk reorganizasyon enerjisinden yüksek olduğunu göstermiş olup hesaplanan reorganizasyon enerji değerleriyle tutarlıdır. Reorganizasyon enerjisinin çoğu karbon-karbon bağlarındaki değişimden kaynaklanmaktadır.

Şekil 4. Hekzasen molekülünde bağ uzunluklarının belirlenmesi.

Tablo 5. Moleküllerin bağ uzunluğu değişiklikleri analizi

\begin{tabular}{|c|c|c|c|c|c|}
\hline İndeks & Nötr & Katyon & Anyon & $\Delta(K-N)$ & $\Delta(A-N)$ \\
\hline \multicolumn{6}{|c|}{ H } \\
\hline $\mathbf{a}$ & 1.36112 & 1.37001 & 1.37280 & 0.00889 & 0.01168 \\
\hline b & 1.43300 & 1.42154 & 1.42093 & 0.01146 & 0.01207 \\
\hline d & 1.43589 & 1.42441 & 1.42646 & 0.01148 & 0.00943 \\
\hline e & 1.38417 & 1.39775 & 1.39876 & 0.01358 & 0.01459 \\
\hline h & 1.40525 & 1.40215 & 1.40510 & 0.0031 & 0.00015 \\
\hline \multicolumn{6}{|c|}{ FH } \\
\hline $\mathbf{a}$ & 1.35756 & 1.37009 & 1.36643 & 0.01253 & 0.00887 \\
\hline b & 1.43085 & 1.42094 & 1.41625 & 0.00991 & 0.0146 \\
\hline c & 1.35756 & 1.37009 & 1.36642 & 0.01253 & 0.00886 \\
\hline d & 1.43015 & 1.41897 & 1.42017 & 0.01118 & 0.00998 \\
\hline h & 1.40514 & 1.40223 & 1.40470 & 0.00291 & 0.00044 \\
\hline \multicolumn{6}{|c|}{ BH } \\
\hline $\mathbf{a}$ & 1.36816 & 1.38072 & 1.37938 & 0.01256 & 0.01122 \\
\hline b & 1.45044 & 1.44096 & 1.43137 & 0.00948 & 0.01907 \\
\hline c & 1.36815 & 1.38073 & 1.37939 & 0.01258 & 0.01124 \\
\hline d & 1.44369 & 1.43224 & 1.43101 & 0.01145 & 0.01268 \\
\hline e & 1.38390 & 1.39774 & 1.39649 & 0.01384 & 0.01259 \\
\hline f & 1.41369 & 1.40215 & 1.40653 & 0.01154 & 0.00716 \\
\hline $\mathbf{g}$ & 1.39526 & 1.40388 & 1.40207 & 0.00862 & 0.00681 \\
\hline h & 1.40553 & 1.40247 & 1.40476 & 0.00306 & 0.00077 \\
\hline \multicolumn{6}{|c|}{ KH } \\
\hline
\end{tabular}




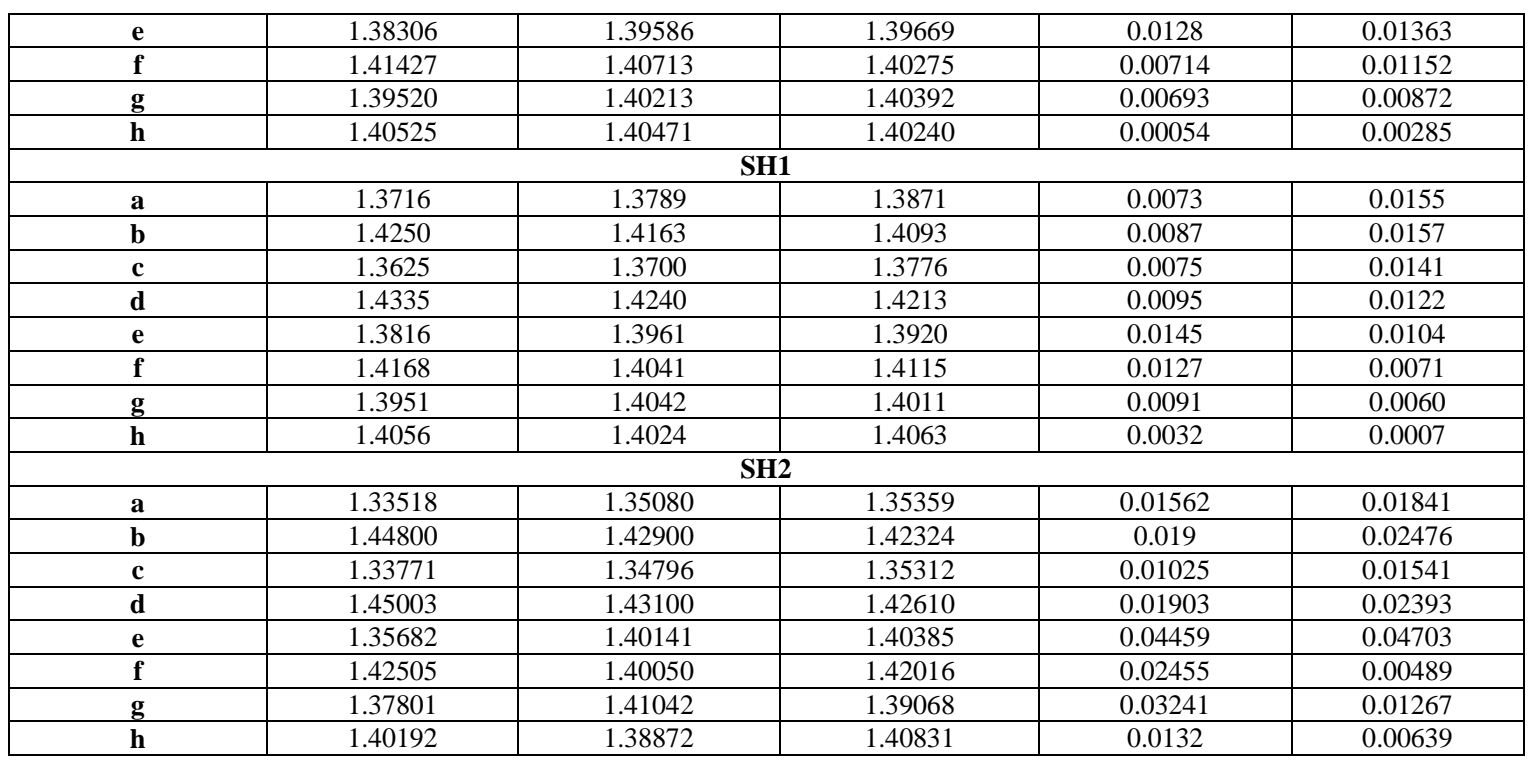

Hesaplanan sonuçlar, hekzasen molekülüne bağlanan halojen atomların ve farklı noktalarda konumlandırılan siyano gruplarının moleküllerin geometrisinde önemli değişikliğe yol açtı̆̆ını ve bu değişikliğin farklı boşluk ve elektron reorganizasyon enerji değerlerinin oluşmasına sebep olduğunu göstermiştir. Dizayn edilen moleküllerde bağ uzunluğu değişim enerjisindeki fark, band aralığı enerji değerinin de düşmesine katkı sağlamıştır.

\section{Sonuç ve Yorum}

$\mathrm{Bu}$ çalışmada, yeni dizayn edilen hekzasen türevlerinin yük transfer özellikleri ana molekül olan hekzasen molekülüyle kıyaslanarak mikroskobik bir bakış açısıyla incelenmiştir. Moleküler geometri, HOMO ve LUMO enerjileri, reorganizasyon enerji değerleri, iyonizasyon potansiyelleri, elektron afinite değerleri Yoğunluk Fonksiyon Teorisi yöntemiyle hesaplanmıştır. Dizayn edilen moleküllerde absorpsiyon dalga boyu, ana moleküle (hekzasen) kıyasla kırmızıya doğru kayma göstermiştir. Moleküllerin yük transfer özellikleri, reorganizasyon enerji değerinden yola çıkılarak Marcus Teoremi'ne göre analiz edilmiştir. Hesaplanan sonuçlara göre, halojen grup bağlanan hekzasen moleküllerinin yük transfer oranı ana molekül olan hekzasenin yük transfer oranından yüksek bulunmuştur. Moleküllerin yük transfer oranları iyi bir yük transfer özelliğine sahip antrasen molekülü ile kıyaslanabilir derecede olup, klor bağlanan molekülün antrasen molekülüyle neredeyse aynı reorganizasyon enerji değerine sahip olduğu belirtilmiştir. Moleküllerin boşluk reorganizasyon enerji değeri elektron reorganizasyon enerji değerinden küçük olduğundan dolayı, moleküllerdeki yük taşıyıcıların boşluklar olduğu belirtilmiştir ( $p$ tip moleküller). Güçlü elektron çekici atom ve grup bağlandığında moleküllerin band aralık değerlerinin de düştüğü gözlenmiştir. İyonizasyon potansiyel enerji değerleri ve elektron afinite değerlerinden yola çıkarak, bu moleküllerin elektron enjeksiyon bariyerinin düşük, dolayısıyla yük transfer oranının yüksek olduğu gösterilmiştir. Sonuç olarak, yapı-özellik ilişkisi incelenen bu moleküllerin, optoelektronik alanda potansiyel uygulamalar için ilgi çekebileceğini ve malzeme biliminde umut vaad edeceğini umuyorum.

\section{Araştırmacıların Katkı Oranı Beyanı}

Makaledeki tüm çalışmalar tarafımdan gerçekleştirilmiştir.

Gül Yakalı: Kavramsallaştırma, Metodoloji, Doğrulama, Biçimsel Analiz, Araştırma, Veri İyileştirme, Orijinal Taslak Yazımı, İnceleme ve Düzenleme, Görselleştirme, Denetim/Gözlem/Tavsiye. 


\section{Destek ve Teşekkür Beyanı}

Bu çalışmada, teorik hesaplamalarda ki teknik desteklerinden dolayı Dokuz Eylül Üniversitesi, Fen Fakültesi'nde çalışan Doç. Dr. Muhittin Aygün'e teşekkürlerimi sunarım.

\section{Çatışma Beyanı}

$\mathrm{Bu}$ çalışmanın yazarı olarak herhangi bir çatışma beyanımın bulunmadığıı bildiririm.

\section{Etik Kurul Onayı ve/veya Aydınlatılmış Onam Bilgileri}

Bu çalışmanın yazarı olarak herhangi bir etik kurul onayı ve/veya aydınlatılmış onam bilgileri beyanım bulunmadığını bildiririm.

\section{Kaynakça}

[1] K. Takimiya, S. Shinamura, I. Osaka, and E. Miyazaki, "Thienoacene-based organic semiconductors," Adv. Mater., 23(38), 4347-4370, 2011.

[2] J. E. Anthony, "Functionalized acenes and heteroacenes for organic electronics," Chem. Rev., 106(12), 5028-5048, 2006

[3] C. Wang, H. Dong, W. Hu, Y. Liu, and D. Zhu, "Semiconducting $\pi$-conjugated systems in fieldeffect transistors: A material odyssey of organic electronics," Chem. Rev., 112(4), 2208-2267, 2012.

[4] L. Wang, G. Duan, Y. Ji, and H. Zhang, "Electronic and charge transport properties of perixanthenoxanthene: The effects of heteroatoms and phenyl substitutions," J. Phys. Chem. C, 116(43), 22679-22686, 2012.

[5] C. R. Newman, C. D. Frisbie, D. A. Da Silva Filho, J. L. Brédas, P. C. Ewbank, and K. R. Mann, "Introduction to organic thin film transistors and design of n-channel organic semiconductors," Chem. Mater., 16(23), 4436-4451, 2004.

[6] M. K. Corpinot and D. K. Bučar, "A Practical Guide to the Design of Molecular Crystals," Crys. Growth Des., 19(2), 1426-1453, 2019.

[7] L. Huang, D. Rocca, S. Baroni, K. E. Gubbins, and M. B. Nardelli, "Molecular design of photoactive acenes for organic photovoltaics," J. Chem. Phys., 130(19), 2009.

[8] J. Roncali, "Molecular engineering of the band gap of $\pi$-conjugated systems: Facing technological applications," Macromol. Rapid. Commun., 28(17), 1761-1775, 2007.

[9] R. Jin and A. Irfan, "Molecular design of organic small molecules based on diindole-diimide with fused aromatic heterocycles as donors for organic solar cells," RSC Adv., 7(63), 39899-39905, 2017.

[10] Y. Cheng, Y. Qi, Y. Tang, C. Zheng, Y. Wan, W. Huang and R. Chen, "Controlling Intramolecular Conformation through Nonbonding Interaction for Soft-Conjugated Materials: Molecular Design and Optoelectronic Properties," J. Phys. Chem. Lett., 7(18), 3609-3615, 2016.

[11] J. Vollbrecht, H. Bock, C. Wiebeler, S. Schumacher, and H. Kitzerow, "Polycyclic aromatic hydrocarbons obtained by lateral core extension of mesogenic perylenes: Absorption and optoelectronic properties," Chem. Eur. J., 20(38), 12026-12031, 2014.

[12] S. Armakovi, S. J. Armakovi, and S. S. Pelemiš, "Transport properties of pentacene, hexacene and their Bn analogues," Contemporary materials, 1(7), 37-44, 2017.

[13] M. Bendikov, H. M. Duong, K. Starkey, K. N. Houk, E. A. Carter, and F. Wudl, "Oligoacenes: Theoretical prediction of open-shell singlet diradical ground states," J. Am. Chem. Soc., 126(24), 7416-7417, 2004.

[14] H. Qu and C. Chi, "Synthetic chemistry of acenes and heteroacenes," Current Organic Chemistry, 14(18), 2070-2108, 2010.

[15] T. J. Chow, "Semiconducting Properties," Acc. Chem. Res., 46(7), 1606-1615, 2013.

[16] Y. H. Park, Y. H. Kim, S. K. Kwon, I. S. Koo, and K. Yang, "Theoretical studies on dicyanoanthracenes as organic semiconductor materials: Reorganization energy," Bull. Korean Chem. Soc., 31(6), 1649-1656, 2010.

[17] J. L. Brédas, "Relationship between band gap and bond length alternation in organic conjugated polymers," J. Chem. Phys., 82(8), 3808-3811, 1985.

[18] J. P. Ferraris and T. L. Lambert, "Poly-4-dicyanomethylene-4H-cyclopenta[2,1-b ;3,4=b']dithiophene (PCDM)," J. Chem. Soc., Chem. Commun., 1268-1270, 1991.

[19] T. L. Lambert and J. P. Ferraris, "Narrow Band Gap Polymers : polycyclopenta [ 2 , 1-b ; 3 , 4-b '] dithiophen-4-one," J. Chem. Soc., Chem. Commun., 752-754, 1991.

[20] J. L. Brédas, A. J. Heeger, and F. Wudl, "Towards organic polymers with very small intrinsic 
band gaps. I. Electronic structure of polyisothianaphthene and derivatives," J. Chem. Phys., 85(8), 4673-4678, 1986.

[21] Y. C. Chang and I. Chao, "An important key to design molecules with small internal reorganization energy: Strong nonbonding character in frontier orbitals," J. Phys. Chem. Lett., 1(1), 116-121, 2010.

[22] Y. Kashiwagi, K. Ohkubo, J. A. McDonald, I. M. Blake, M. J. Crossley, Y. Araki, O. Ito, H. Imahori and S. Fukuzumi, "Long-lived charge-separated state produced by photoinduced electron transfer in a zinc imidazoporphyrin-C60 dyad," Org. Lett., 5(15), 2719-2721, 2003.

[23] W. Diirckheimer, "Tetracyclines chemistry biochemistry and structure-activity relations,"Angew. Chem. Int. Ed., 14(11), 721-774, 1975.

[24] Y. A. Berlin, G. R. Hutchison, P. Rempala, M. A. Ratner and J. Michl, "Charge hopping in molecular wires as a sequence of electron-transfer reactions," J. Phys. Chem. A, 107(19), 39703980, 2003.

[25] E. V. Tsiper, Z. G. Soos, W. Gao, and A. Kahn, "Eletronic polarization at surfaces and thin films of organic molecular crystals: PTCDA,” Chemical Physics Letters, 360(12), 47-52, 2002.

[26] C. Lee, W. Yang, and R. G. Parr, "Development of the Colle-Salvetti correlation-energy formula into a functional of the electron density," Physical Review B, 37(2), 785-789, 1988.

[27] B. Miechlic, A. Savin, H. Stoll, H. Preuss, "Results obtained with the correlation energy density functionals of becke and Lee, Yang and Parr," Chemical Physics Letter, 157(3), 200-206, 1989.

[28] J. Antony and S. Grimme, "Density functional theory including dispersion corrections for intermolecular interactions in a large benchmark set of biologically relevant molecules," Phys. Chem. Chem. Phys., 8(45), 5287-5293, 2006.

[29] G. A. Petersson, A. Bennett, T. G. Tensfeldt, M. A. Al-Laham, W. A. Shirley, and J. Mantzaris, "A complete basis set model chemistry. I. The total energies of closed-shell atoms and hydrides of the first-row elements," J. Chem. Phys., 89(4), 2193-2218, 1988.

[30] R. A. Marcus and N. Sutin, "Electron transfers in chemistry and biology," BBA-Bioenergetics, 811(3), 265-322, 1985.

[31] J. P. Calbert, D. A. S. Filho, J. Cornil, and J. L. Bre, "Organic semiconductors : A theoretical characterization of the basic parameters governing charge transport," PNAS, 99(9), 5804-5809 2002.

[32] B. C. Lin, C. P. Cheng, Z. Q. You and C. P. Hsu, "Charge transport properties of Tris ( 8hydroxyquinolinato ) aluminum ( III ): Why it is an electron transporter," J. Am. Chem. Soc., 127(1), 66-67, 2005.

[33] Y. Mao, M. Head-Gordon, and Y. Shao, "Unraveling substituent effects on frontier orbitals of conjugated molecules using an absolutely localized molecular orbital based analysis," Chem. Sci., 9(45), 8598-8607, 2018.

[34] H. B. Michaelson, "The work function of the elements and its periodicity," J. Appl. Phys., 48(11) , 4729-4733, 1977.

[35] W. C. Chen and I. Chao, "Molecular orbital-based design of $\pi$-conjugated organic materials with small internal reorganization energy: Generation of nonbonding character in frontier orbitals," $J$. Phys. Chem. C, 118(35), 20176-20183, 2014.

[36] S. Kera et al., "Experimental Reorganization Energies of Pentacene and Per fluoropentacene: Eff ects of Perfluorination," J. Phys. Chem. C, 117(43), 22428-22437, 2013.

[37] R. Mondal, C. Tönshoff, D. Khon, D. C. Neckers, and H. F. Bettinger, "Synthesis, stability, and photochemistry of pentacene, hexacene, and heptacene: A matrix isolation study," J. Am. Chem. Soc., 131(40), 14281-14289, 2009. 